\title{
Second Language Learning and Second Language Learners: Growth and Diversity
}

Rod Ellis

The field of second language acquisition (SLA) studies is characterized by two different traditions. One tradition is linguistic and focusses on the process by which learners build up their linguistic knowledge of the second language (L2). Here the focus is on learning. Human beings are credited with an innate capacity to learn language which explains why the process of learning manifests distinct structural regularities. Human beings also possess a common set of wants and needs, which they express through language; this, in turn, accounts for commonalities in the way the L2 is used. The other tradition is psychological; it focusses on the different ways in which learners cope with the task of learning and using an L2. Here the focus is on the learner. Human beings are individuals; they differ with regard to gender, age, motivation, personality, learning style, self-esteem etc. Each person has her own way of going about things with the result that there is immense diversity in both the way learners learn and in what they achieve. The teacher needs to take account of both of these traditions-she needs to consider how learners learn and she needs to consider how they differ.

The two traditions may appear, at first sight, to be in conflict. How can we talk about the universal properties of SLA while at the same time admitting that learners are inherently different? There is no conflict, however. Seliger (1984) distinguishes strategies and tactics. The former involve subconscious mechanisms which govern how input becomes intake. They are not open to direct inspection. Instead, we have to infer what they consist of by studying the learner's output. Learning strategies can be seen as part of the cognitive process in which learners form, test and revise hypotheses (Faerch and Kasper, 1980). Alternatively they can be explained with reference to the setting of parameters available to the learner as part of Universal Grammar (Flynn 1988). Irrespective of which kind of explanation is offered, the assumption is that all learners work on the input data available to them in the same way. Tactics, according to Seliger, are the devices a learner uses to obtain input and to help them make sense of it. They are conscious-or potentially conscious-and they are open to inspection, therefore. Learners use tactics to plan their learning, to monitor their progress, to tackle specific learning tasks and to 
compensate for communication problems. Tactics are highly variable. No two learners adopt precisely the same set of tactics. Tactics account for why learners vary in the speed with which they acquire a L2.

The two traditions have helped to support different approaches to language instruction. Prabhu (1985) distinguishes learner-centred and learning-centred approaches. The former is expressed in the language for specific purposes movement; it involves the attempt to identify the needs of individual learners (or groups of learners) and the design of tailor-made courses to meet these needs. It is also evident in the attempt to adapt the teaching method to the learner's learning style, as in Wesche's (1981) study of deductive and inductive learners, who were exposed to instruction that emphasized respectively conscious rule-formation and audiolingual practice. Learning-centred methodologies are based on theories of the learning process. Humanistic approaches are grounded on a general view of how learning-of any kind-takes place. They seek to create the conditions, particularly the affective conditions, needed to ensure successful learning. Other learning-centred approaches emphasize the uniqueness of language. They treat language learning as a distinct kind of learning. The pedagogical proposals advanced by Stephen Krashen are a good example of an approach based on a theory of language learning.

In this paper I want to try to explore both traditions in order to argue that a 'whole' approach to language teaching must give consideration to both the structural nature of learning and the learner qua individual.

\section{Learning}

The last twenty years have seen a burgeoning of interest in how learners learn an L2. This interest has been generated in part by the importance of foreign language learning (particularly English) in the modern world and in part by the paradigm clashes first between behaviourist and nativist views of language learning and more recently between cognitive and linguistic explanations. There have been an increasing number of empirical studies designed to investigate how learners acquire a knowledge of the L2. There have also been a plethora of theories to explain how it takes place. It would be impossible to provide an adequate 'state-of-the-art' summary in the time available, so instead I will outline and illustrate two general models of SLA, which characterize much of the current research.

The two models involve very different views of what it means to 'develop' an L2 (Ellis, 1989a). According to one view, learners acquire a knowledge of the L2 incrementally, systematically adding new rules to their grammar. I will refer to this as 'development-as-sequence'. According to the other view, L2 learning is not so much a process of adding new rules to existing ones as of gradually complexifying a mental grammar of the 
L2. Specific structures or sets of features within a linguistic sub-system complexify through the accummulation of new features. The process involves the constant reformation of existing knowledge as new knowledge enters the system. I will refer to this model of SLA as 'development-asgrowth'.

\section{Development-as-sequence}

The development-as-sequence model is evident in the morpheme studies which were popular in the 70s. These studies collected cross-sectional data from groups of learners, identified obligatory contexts for the use of specific morphemes such as aux-be, plural $-s$ and past regular $-e d$ and then worked out how accurately each morpheme was produced. Accuracy orders were then drawn up by ranking the morphemes. Some researchers (e.g. Dulay and Burt, 1973) went on to claim that the accuracy order represented the order of acquisition, on the grounds that morphemes that were acquired first would be performed more correctly than morphemes that were acquired later. A number of different groups of subjects were investigated in this way. The accuracy order obtained was remarkably stable-it was obtained irrespective of the learners' L1s or whether they were children or adults. Researchers such as Krashen (1977) used the results of the morpheme studies to claim that there was a 'natural' route of acquisition for a L2.

The morpheme studies are now out of favour. They have been attacked on a number of grounds. In particular, equating accuracy and acquisition orders has been challenged. It has been shown that the acquisition of specific features is characterized by a U-shaped pattern of development, such that learners initially perform a feature with a high level of accuracy, which then falls away until a fairly late stage when it emerges once again correctly in their speech. It has also been shown that the acquisition of a specific form does not necessarily mean that learners have acquired the ability to use the form in a target-like way. For example, a learner may correctly use the progressive -ing form in sentences like:

I am colouring my picture.

She is reading.

but also over-use the same form in sentences like:

Sharpening my pencil ( $=$ sharpen my pencil.)

I playing football every day. ( $=$ I play football every day.)

Wagner-Gough (1975), in a study of a 6 yr. old Persian boy learning English in the USA, found that the progressive-ing was used for a wide variety of functions in the early stage of acquisition-to express immediate intention, distant futurity, pastness, process-state activity and commands. 
These are significant criticisms and we would do well not to put too much faith in the morpheme studies.

It does not follow, however, that we have to completely abandon the development-as-sequence model. There is, in fact ample evidence to suggest that certain formal properties of a L2 are acquired sequentially in some kind of natural sequence. The best evidence comes from studies of the acquisition of German word order rules by both naturalistic and classroom learners (Meisel, 1983; Pienemann, 1983; Ellis, 1989b). The following stages have been found:

(1) SVO (A)

Initially learners follow a 'canonical' word order, which it is suggested corresponds to some natural way of perceiving the world. The order is subject-verb-object. If an adverbial is used it follows the object.

(2) Adverb preposing

Next the learners learn how to place adverbs in sentence initial position.

(3) Particle

In German particles (consisting of prepositional particles, infinitives or past participles) are positioned at the end of their clause. They are therefore separated from the main lexical verb.

(4) Inversion

Subject-verb inversion occurs in a number of different linguistic contexts-in interrogatives, and after a sentence-initial adverb, for instance.

(5) Verb-end

The finite verb is placed in final position in subordinate clauses.

Learners with different L1s show an amazing consistency in the sequence of acquisition of these word order rules. Each rule, it is suggested, involves certain processing operations which are hierarchical in terms of their psycholinguistic complexity. The acquisition of one set of operations serves as a prerequisite for the acquisition of the subsequent set. A number of studies have been conducted to investigate whether instruction in advanced word order rules can enable a learner to jump stages or to learn the rules in a different order (e.g. Pienemann, 1984; Ellis, 1989b). The results indicate that this is not possible.

The restrictions imposed by processing limitations and the way in which learners slowly overcome them is apparent in all longitudinal case studies of L2 learners. In my own research I investigated the acquisition of English by three classroom learners in a London language centre. I found clear 
evidence to support the idea of a sequence of development. For example, the learner's ability to produce imperatives of the kind:

Sir, don't tell Mariana the answer please.

(Vocative) + (neg) $+\mathrm{V}+(\mathrm{NP})+(\mathrm{NP})+$ (please)

was characterized by clearly-defined stages:

Stage (1): One element only is encoded, usually the vocative or the object of the required action.

e.g. Sir, sir, sir.

Stage (2): Two elements only are encoded, usually the vocative or the object of the required action. Imperatives are typically verbless at this stage.

e.g. Sir, sir, pencil.

Stage (3): Imperatives with verbs appear-the verb taking the imperative or progressive-ing form. By this stage the learners are also able to produce three-element strings.

e.g. Sharpening please.

Playing football with sir today.

Stage (4): A negative particle is used with a verb to form a negative command.

e.g. No looking my card.

The general pattern of development is reminiscent of child L1 acquisition. Learners gradually increase their processing capacity and, in so doing, are able to produce more and more complex structures.

The idea of a 'natural' route of acquisition is not one that all L2 researchers would wish to adhere to. Lightbown (1984) has pointed out that for every study that gives evidence of a standard sequence, there is another that provides counterfactual evidence. There is, however, sufficient evidence to suggest both that there is a general pattern of development and, for some structures at least an order of acquisition. It does not follow, however, that all grammatical properties are acquired sequentially-indeed it would seem likely that there are many features that are not subject to the kinds of processing constraints discussed above.

\section{Development-as-growth}

The development-as-sequence model focusses on the formal properties: of language, but, if we are to understand fully how learners acquire the competence to use the L 2 we need to consider not just forms but also the 
functions to which they are put. It is when we look at the inter-relationship between form and function in a learner's interlanguage, that we see that development involves an organic process of growth. The task facing the learner is to sort out the form-function correlations that accord with target language use. But this takes time. The interim grammars that learners build are functional grammars; they consist of networks of functions linked loosely to networks of linguistic forms. As the learner gradually builds her interlanguage, she reorganizes the existing network. One way of characterizing the successful language learner is as someone who is able to correlate a range of forms with a range of functions (Nicholas, 1986).

It is possible to identify three major processes in development-asgrowth:

1) Innovation (i.e. the introduction of new forms into the interlanguage system).

2) Elaboration (i.e. the extension of the communicative base of the new form).

3) Revision (i.e. the adjustments to the entire interlanguage system resulting from innovation and elaboration).

These processes are not stages; they are overlapping and continuous. Thus while one form is entering the learner's interlanguage, other forms are in the process of becoming elaborated and revision of the system also starts to take place.

The underlying principle of the development-as-growth model is that learners need to perform certain communicative functions and will use whatever resources are at their disposal to do so. Learners have the capacity to create meaning out of whatever linguistic means they possess-in much the same way as any user of language has (Widdowson, 1978). Gradually, these means will become more target-like. One of the primary motivations for acquiring new resources is to extend the range of pragmatic meanings that can be expressed. The acquisition of new linguistic means results, in turn, in a readjustment of existing resources in order to achieve maximal communicative effectiveness. The need for communicative choice, is, therefore the driving force of development-as-growth. If learners lose this desire-because subconsciously or consciously they feel they have achieved sufficient resources to meet their communicative needs, then fossilization takes place. The learner closes herself off from target language norms and her interlanguage stops growing.

As an example of how this kind of growth takes place let us consider how the three children referred to earlier set about performing the network of meanings relating to the expression of negation. Bloom (1970) identified three broad categories of negation: 
1) Non-existence

This can be further sub-divided according to whether the speaker asserts the non-existence of an action-process:

e.g. Mariana no coming today.

or the non-existence of a state-process:

e.g. Miss, no pens. ( = Miss, I don't have a pen).

I no understand.

2) Rejection

This can be broken down into instrumental (i.e. the speaker asserts a negative wish):

e.g. Me no out of here.

and regulation (i.e. the speaker tries to control the actions of another person):

e.g. Don't touch.

3) Denial (i.e. where the speaker refutes or corrects what someone else has said)

e.g. No, eleven. ( = My team hasn't got ten points. It's got eleven.)

To start with, the three learners did not realize the full range of these meanings. Their earliest negatives expressed-instrumental needs and the non-existence of state-process events. Regulatory negatives appeared a little later. Reference to the non-existence of action-processes emerged last. This pattern of development was consistent across the three children. It can be explained largely by the communicative needs of the children in the classroom context. Initially, classroom survival calls for the learner to be able to express non-possession ('No have ...'), non-knowledge ('I don't know') and negative wishes ('No want ...'). As the learner grows into her environment, she needs to be able to exert her control over other people ('No do ...'). Being able to comment on non-events ('X no happen ...') is of less immediate interpersonal value to the learner and therefore does not occur until later.

If we turn to the linguistic resources the learners used to realize these meanings, we find evidence of an interesting relationship between form and function. The ubiquitous 'no' negator is used in utterances that perform all the functions listed above. The learners also picked up formulas for performing a number of key functions:

e.g. I don't know.

I don't like.

I don't want. 
Other negators like 'don't' and 'not' were initially used in free variation with 'no';

e.g. No look my card.

Don't look my card.

but in a restricted manner. They were used principally in regulatory utterances. Not until much later did 'not' begin to be used according to target language norms. The learners, then, created their own system-a system that can only be understood if function as well as form is considered. The main characteristic of this system is that it sought to make use of whatever resources the learners had available in order to distinguish different kinds of meaning, though the manner in which this was done did not at first correspond to target-language use.

To understand how development-as-growth takes place, therefore, we have to see the language learner as a communicator. Initially the learner has few resources so she relies on her ability to exploit the meaning situated in the context of utterance. To facilitate communication she also acquires a set of useful formulas. As resources are built up she seeks to put them to maximum use by building form-function networks. These networks are constantly evolving as the learner acquires new resources and seeks to express increasingly complex ideas. Normally, we can expect the classroom L2 learner to give primacy to interpersonal meanings to start with. The ideational and textual functions of language follow later. The whole process of syntactization is inextricably linked with the process of learning how to communicate (Givon, 1979).

\section{Summary}

To summarize, the development-as-sequence model claims that learners follow some kind of 'natural' route as a result of the processing complexity of different structures. It emphasizes the significance of linguistic factors as determinants of acquisition. The development-as-growth model sees language development as part of the process of learning how to communicate. It attaches importance, therefore, to the changing patterns of interrelationship of form and function. Both models are valid; they both capture important structural facts about the process of SLA.

\section{The learner}

Let us now turn away from the structural facts and consider in what ways learners vary in the way they go about learning an L2. I want to consider two questions.

1) In what ways do learners differ in their approach?

2) Are some approaches better than others? 


\section{Learning style}

One way we can try to answer the first question is by considering learning style. This refers to the idea that learners have characteristic ways of tackling problems which reflect their whole selves-it is the product of their cognitive, social and physiological preferences. A learner's learning style is evident in whatever she is doing-whether it is learning how to swim or how to learn a language. It is partly the product of innate disposition and partly of experience. A learner's previous education, for instance, may have led her to form certain expectations about what it means to learn in a formal setting. There is a rich psychological literature dealing with learning style (cf. Witkin et al, 1977; Kolb, 1976; Gregorc, 1979) which is of considerable potential interest to L2 researchers and teachers, but, for reasons of space, I will concentrate here on ideas derived directly from the study of L2 learners.

Learning style can be usefully discussed in terms of the learner's cognitive and affective orientations to the task of learning an L2.

\section{Cognitive orientation}

It is possible to draw a basic distinction between experiential and studial learners.

Experiential learners are concerned primarily with learning how to communicate in the L2. They believe that the best way to learn is through using the language. However, using does not necessarily mean speaking or writing; an experiential learner can also elect to learn through active listening and reading. Experiential learners are likely to be people-oriented and to dislike routinized learning. They are data-gatherers, acquiring useful formulas and vocabulary rather than rules. They are not bothered about making errors and tend to be monitor under-users. Experiential learners are primarily concerned with meaning and fluency rather than form and accuracy.

Studial learners believe that it is important to approach the task of learning the L2 in a systematic way. They seek direction and consciously plan how they will learn. They try to identify specific problems and to deal with them. Thus, they are likely to make use of reference books (grammars and dictionaries) and to keep notes of useful words and phrases. They are usually object-oriented. They are rule-formers, making efforts to consciously understand grammatical structures, often by comparing the way the L2 works with their mother tongue. They dislike making errors and try to avoid them. They tend to be monitor over-users and they like other people to correct them. Studial learners are primarily concerned with form and accuracy rather than meaning and fluency.

This basic distinction between experiential and studial learners is 
reflected in a wide range of SLA studies. It has been observed in longitudinal case studies of individual learners (Hatch, 1974), in studies of L2 productions (Dechert, 1984) and in studies based on interviews with learners (Wenden, 1986). It is not intended to suggest, however, that learners fall into one of two camps-experiential or studial. Many learners are 'balanced' learners in the sense that they operate both experientially and studially, in accordance with the particular task or situation in which they find themselves. It may also be the case that learners vary in their cognitive orientation at different stages of their learning, starting off, for instance, as studial learners and then becoming more experiential later. We know little about this, however.

\section{Affective orientation}

Willing (1988), using Likert-scale type questionnaires, investigated 517 adult ESL learners in Australia and found that some of them could be distinguished according to the experiential-studial distinction. In the case of many of the learners, however, another dimension was also involved. The learners also differed according to how active they were in their approach to learning. The active-passive dimension, then, is also an important aspect of diversity. This dimension reflects the learner's overall affective orientiation to the learning task.

Active learners are independent, are able to tolerate the inherent ambiguity in language, persist in problem solving and enjoy taking decisions. They are self-directed and able to manage their own learning. It should be noted, however, that active does not just mean active in production; a learner can also be an active listener or an active reader. Passive learners, on the other hand, tend to be reliant on others, are intolerant of ambiguity, like the teacher to explain everything and do not enjoy discovery learning. Again, it should be noted that passivity does not necessarily mean that learners are not prepared to speak or write in the L2, only that they prefer someone else to take charge of what they have to do.

The extent to which a learner is active or passive is probably, in part at least, a product of their personality. But it is also a reflection of their attitude to the language, to native speakers of the language and to the style of instruction they are receiving. Learners approach the task of learning a new language with certain attitudes, which may be positive or negative. These constitute their initial affective disposition. As a result of their experiences while trying to learn the language, their initial attitudes may be reinforced or they may be modified. Whereas a learner's cognitive orientation is relatively stable, her affective orientation is unstable. Learners fluctuate enormously on both a day-to-day basis and over a longer period of time. It is not possible, therefore, to talk about learners who are 
permanently active or permanently passive. We should rather see individual learners as variable on this dimension.

As an example of how learners vary in their affective orientation let us consider Mary, a learner of German as an L2 in higher education in London. Mary kept a diary of her learning experiences for six months. She started off with what is clearly a very positive attitude:

I've really been enjoying learning a new language again. It almost feels as if I'm reliving part of my childhood.

Her diary shows how this attitude is reflected in a highly active approach to learning. The early entries make regular references to self-study. Also the competition and pressure which the instructional style encourages have a positive effect on her. She writes:

I find the competitiveness is helping me to feel obliged to work all the harder.

However, as time passes, her attitudes begin to change. She becomes resentful of the disruptive behaviour of a number of male students in her group and objects to time being wasted because the teacher had to explain points they had missed through poor attendance. Her diary shows a growing sense of frustration. Also she has personal problems with her boyfriend and this has a damaging effect on her ability to concentrate:

I've been really nervous today. I've got terrible butterflies and I can't stop shaking. I was in no mood for a German lesson . . .

At this stage the diary shows that her mood fluctuates markedly on a daily basis.

By the end of six months, however, her affective response has become consistently negative. The main reason appears to be her resentment of the pressure imposed upon her, linked to the fact that, for her, German is an optional subject which she intends to give up at the end of the academic year. Slowly, then, she turns from being an active, conscientious learner to a much more passive, laissez-faire one. This is what she says at the end of her diary:
... seeing as I don't want to study it seriously, I can't see the point of working so hard for it anymore. I haven't done any German home- work for weeks. It is my own loss I know, but I can't see the point in doing it anymore. We've been pushed too hard and at last I've broken down. I've lost all my good attitudes and intentions about German lessons that I had before.

This diary shows us just how important affective factors are in determining whether a learner is active or passive in her approach. It shows also 
that the degree of activity/passivity is determined to a large extent by local factors in the personal life of the learner and in the learning environment. In a way this is encouraging, because it suggests that, with sensitive handling, positive attitudes can be fostered.

Learners, then vary according to what extent they are experiential or studial on the one hand and active or passive on the other. These dimensions are to be seen as intersecting continua. Individual learners can be plotted with relation to where they come on the two continua (see Figure 1). Thus, at the extremes we will find active experiential learners, passive experiential learners, active studial learners and passive studial learners. The vast majority of learners, of course, will not fall at the extremes but somewhere in between. Also, learners will change during the course of their learning.

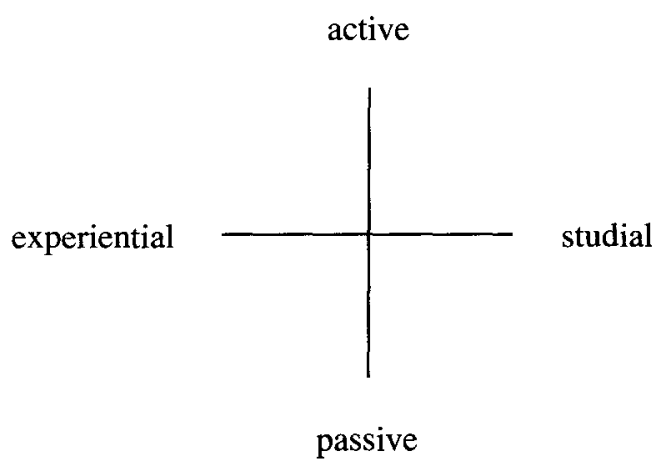

Figure 1: Types of learning style in SLA

\section{The 'good language learner'}

So far we have been content to describe how learners' learning styles vary. But we also need to know whether some approaches to the learning task work better than others. The last fifteen years have seen a number of studies of the 'good language learner' (e.g. Rubin, 1973; Stern, 1975; Naiman et al, 1978; Reiss, 1985; Abraham and Vann, 1987). These provide a remarkably consistent picture of the tactics used by successful language learners.

In general, the studies point to four key aspects:

(1) A concern for language form

The good language learner pays attention to form. Indeed, according to Reiss' (1985) study, learning tactics reflecting this approach came out on top in a group of 98 college students studying a foreign language at an elementary or intermediate level. The two strategies the learners reported 
using most frequently were monitoring and attending to form. Other researchers have also found form-focussing tactics a regular feature of the successful language learner. Naiman et al (1978), for instance, mention that learners who treat language as a system engage in effective cross-lingual comparisons, analyze the target-language and make frequent use of reference books. These learners also tried to learn from their errors by asking native speakers to correct them.

\section{(2) A concern for communication}

Good learners also attend to meaning. Attention to form and to meaning are not mutually exclusive. Learners seem to benefit from alternating between the two. Gerardo, the more successful of the two learners investigated by Abraham and Vann (1987), is a good example. He took a broad view of language, paying attention sometimes to form and sometimes to meaning. In contrast, Pedro, the less successful, was more or less exclusively concerned with meaning and getting by in conversations. All the good language studies have found that successful learners search for meaning and try to engage in real communication by seeking out opportunities for natural use. They make efforts to get their meanings across using a variety of communication strategies.

(3) An active task approach

Good learners are active in their approach. This can manifest itself in different ways. Active learners take charge of their own learning, rather than relying exclusively on the teacher. They are persistent in pursuing goals. In conversation, the active learner introduces new topics and tries to control the direction the discourse follows. But being an active learner does not mean participating in terms of language production. Reiss (1985) emphasizes that her successful learners were typically 'silent speakers'. They listened closely in class and mentally answered questions whether called upon to do so or not. They listened to other students and mentally corrected their errors. They tried to apply new material while silently speaking to themselves.

(4) Awareness of the learning process

Finally, good language learners demonstrate considerable awareness of the learning process and of themselves in relation to this process. They are thoughtful learners who make conscious decisions about what to study and what tactics to employ. They are likely to have a well-developed metacognitive language for talking about their learning and this helps them to monitor how they are progressing. Reiss found that her good language learners were able to give very specific descriptions of how they would approach different learning tasks, while the less successful were often vague and imprecise. Metacognitive knowledge is important because it 
enables learners to assess their needs, evaluate their progress and give overall direction to their learning.

\section{Summary}

To sum up, learners vary according to whether they lean towards learning experientially or learning studially. They also vary according to how active they are in their approach. There are many ways of learning an L2 and doubtlessly a learner's approach will reflect what she wants to achieve. A learner who wants to be fluent and is not bothered too much with accuracy will elect to learn experientially if she can. A learner who wants to pass exams and to achieve a high level of proficiency will probably be more studial. There are obvious dangers in suggesting that one learning style is better than another. However, the evidence of the good language learner research suggests that to be successful (in the sense of achieving both accuracy and fluency) learners need to pay attention to both form and meaning, to be active (particularly in attending to input) and to take charge of their own learning. The successful learner-in some absolute sensetherefore will try to strike a balance between experiencing and studying the language and will be active, both in the sense of being highly responsive to input and in being self-directed. There may, however, be many ways of achieving a balance and learners may grow to be active as learning proceeds.

\section{Instruction}

What lessons does the particular view of learning and the learner which I have now presented hold for language pedagogy? First, let me make it clear that I do not see SLA studies of the kind discussed in the previous sections providing definite answers to pedagogical questions. SLA research is only one of many inputs into the process of decision makingteachers ought to and certainly will consider other inputs (e.g. general educational principles and their own practical experience about what works in the classroom. I prefer to treat SLA research as a source of illumination rather than of solutions and to acknowledge that illumination can come from many sources.

In accordance with the theme of this conference Growth and Diversity I would like to address two questions:

(1) How can we help learners to 'grow'-in the sense of helping them to build their interlanguage systems successfully?

(2) How can we cater for diversity-in the sense of taking account of differences in learners' learning style?

In discussing these questions, I will seek only to outline general positions and not to propose methods of specific techniques. 


\section{Helping learners 'grow'}

One of the clearest messages of the existing research is that the process of SLA is controlled by the learner; it is internally rather than externally driven. This is the message of both the development-as-sequence and the development-as-growth models. If learners do progress along a 'natural' route in the process of acquiring an L2 and if this route cannot be rearranged for the learner through instruction, then clearly it is the teacher who has to accommodate to the learner rather than vice-versa. It is also impossible for the teacher to regulate in a direct way the process by which learners build, complexify and rearrange form-function networks. The process of interlanguage development is far too intricate and personal for a teacher to intrude into.

The development-as-sequence model does hold out some possibility of direct pedagogic intervention into language learning, however. Perhaps it is possible to organize the instruction so that it corresponds to the natural sequence. For instance, we could try to teach word order rules in the order in which they are acquired, providing learners with chances to practise each structure at just that moment she becomes ready to learn it. There have been a number of proposals along these lines, the most clearly articulated of which is that of Pienemann's (1985). Pienemann suggests that although there should be no attempt to control structures in the input learners are exposed to, they should only be asked to produce structures which are within their processing capabilities. Structures can be taught when they are learnable. But this proposal, while tenable at the level of theory, is unworkable in practice. We cannot expect teachers to know when each learner in their class is ready to acquire the next rule. Also, the research to date is limited to a relatively small set of grammatical features. What should the teacher do about those structures for which no clear developmental evidence is available? Not surprisingly, perhaps, Pienemann's proposal has not received much support.

Does this mean, therefore, that teachers should abandon all attempts to teach grammar? The answer is no. What the teacher needs to do is to distinguish two approaches to grammar teaching according to whether the instruction is aimed at direct or indirect intervention. Direct grammar teaching is the traditional approach-the one associated in particular with audiolingualism, the legacy of which is still very much with us today. Direct grammar teaching is predicated on the belief that learners can learn a new structure if they produce if often enough, but, as we hve seen, this is a belief which is not supported by the research. Indirect grammar teaching aims to raise the learner's consciousness about the experience of certain forms in the input which are not yet part of her interlanguage. The assumption is that the learner will probably not acquire the forms immediately 
but will be sensitized to their presence in the input, thereby facilitating subsequent learning, when the learner becomes ready to assimilate them into her interlanguage. Grammar teaching as indirect intervention-aimed at delayed rather than immediate acquisition and concerned with raising awareness rather than achieving productive competence - is viable and may even be necessary to prevent early fossilization.

The development-as-growth model suggests the importance of learners having the opportunity to engage in real communication. The process by which form-function networks are constructed and modified is fired by the need to use language to express interpersonal and ideational meanings in the construction of discourse of various kinds. The provision of instructional activities which can serve as the crucible for this process is the main challenge facing the teacher. The thrust of communicative language teaching methodology in the eighties has been to provide the teacher with the means for creating meaning-focussed communication in the classroom. In particular, learners need to have the chance to perform a range of language functions and not to be restricted to 'responding to questions', as happens in so many classrooms (Long and Sato, 1983). Interlanguage growth results from the need to realize different kinds of meaning. If there is no need, there is neither motivation nor opportunity to learn.

How then can the teacher generate in the learners a felt need to communicate in the L2? I would like to suggest the following guidelines:

1) Never force learners to produce. Let each learner decide for herself when she wants to speak.

2) Never force learners to produce in some pre-determined way. Let them choose how to express themselves.

3) Do your best to understand what the learner is trying to say.

4) Help learners to express what they want to say. You can do this by means of requests for confirmation and paraphrasing.

5) Give learners the chance to initiate their own topics.

6) Help learners to extend a topic. You can do this by means of expansions, extensions, prompts and prods. But take care not to push a learner too far.

7) Be prepared to correct learners, but never allow the process of correction to take over from the process of trying to communicate with them.

With the exception of the last point, this list is similar to a list produced by Wells (1986) in his summative guidance to parents who want to help their children learn to talk. Wells argues that children have to work out the way language is organized for themselves, but they need help in doing so. The L2 learner is the same. Of course, the task facing the language teacher is very different from that facing the mother. The teacher only sees the learner a few hours every week. She also has to work in a one-to-many, 
not a one-to-one situation. But the general principles of how to go about facilitating language learning remain the same.

It is worth noting that if we view teaching as a way of providing the learner with an optimal learning environment, we will be rejecting a means-end view of the curriculum in favour of the kind of process orientation that is currently in favour (Breen, 1987; Nunan, 1988). The content of a language programme (as defined in a syllabus or a set of materials) is of considerably less importance than the classroom interactions which occur in the process of teaching. We should also note that these interactions grow out of the management of business and social relationships in the classroom as much as out of the tasks officially designated for learning.

\section{Catering for diversity}

We can cater for diversity in learning style in two different ways. We can seek a match between the instructional style and the learner's learning style-try to ensure, for example, that experiential and studial learners receive appropriate programmes. Alternatively, we can try to train learners to cope efficiently with their own learning and/or, perhaps, to adopt a learning style that we consider most likely to result in successful language learning. The first approach seeks to accommodate diversity, the other tries to help the learner become more effective.

There is no time to explore both of these approaches in detail. There is some research to show that matching instructional and learning styles does promote learning (e.g. Wesche, 1981). There is also a rich literature dealing with the need for learners to be autonomous, so that they can formulate their own aims, choose their own materials and learning methods and carry out self-evaluation of their progress (e.g. Holec, 1980). Such a learner is equipped not only to learn during the course of instruction but also to carry on learning when it is over. We must acknowledge, as teachers, our responsibility to make the learner responsible for her own learning and not encourage teacher-dependency.

It seems to me that interesting as these two approaches are, they will never provide the real answer to diversity in learning styles for most teachers. It is simply not practical for most teachers to try to diagnose the learning styles of their learners, divide them into groups and provide different instructional treatments to match each group.

Learner training directed at making learners more autonomous is more feasible and, probably, more useful, but it is unlikely that most teaching contexts will have sufficient resources to cater for totally self-directed learning. If we want to accommodate diversity, then, we must seek out different answers. 
I think the real answer is to be found in two very general approaches to teaching:

(1) Teachers need to negotiate the learning tasks with the learners. The nature of the negotiation may be relatively formalized in the sense that teachers can actively seek the opinions of learners about what kinds of learning and evaluation activities they would like to participate in. Alternatively, it can take place in a more informal manner, as when a teacher reacts to the different ways in which individual learners respond to tasks selected by the teacher. This informal kind of negotiation serves as the main way in which teachers try to accommodate variation in learning styles. Good teachers have always been sensitive to what works and what does not work with particular learners. They seek to ensure that there is sufficient variety in the kinds of tasks learners are asked to undertake to satisfy all the learners at least some of the time.

(2) Teachers need to adapt the way they communicate to suit individual learners. The teacher who seeks 'a meeting of minds' with her learners does so principally by the way she communicates with them-both collectively and individually. Accommodation to the needs and preferences of individual learners needs to be seen as part of the overall process of communicating with them. To succeed, teachers have to be able to assess not only what each learner is capable of in communication but also his or her personal preferences. To force a learner to produce when she prefers to function as an 'active listener' is potentially damaging. So too would be to prevent the risk-taking learner from playing a prominent role as a speaker. Some learners find teachers' questions threatening; others welcome them. Some learners want to be corrected; others do not. It is through interacting with learners that the process of negotiating an individualized curriculum really takes place. A learner-centred curriculum is not something that is planned (although planning can help), but something that unravels through classroom communication.

It is by negotiating the choice of learning task and by showing sensitivity to individual learners in the way she communicates with them that the teacher can foster a positive affective climate in the classroom. A humanistic classroom is not one where certain rather special kinds of activities take place, but one where learners are valued and nurtured as individuals. A learner is more likely to be active if she feels she has some say in what happens in the classroom and if, day by day, her personal learning style is respected in communication with the teacher.

The idea of an individualized approach to language pedagogy has, I think, always been threatening to teachers-because they have not been 
able to see how it could work in practical terms. In fact, the good teacher has always provided individualized instruction by negotiating formally or informally what is done and by adjusting the way in which it is done in how she communicates with different learners.

\section{Conclusion}

In a sense, then, helping learners to grow and catering for diversity calls for the same set of basic skills from the teacher. In particular, the teacher needs to be a good communicator. The truth of this observation becomes more and more apparent to me as I observe lessons in different parts of the world. Teachers vary enormously in their abilities to communicate effectively in the classroom. Some are expert, able to provide the kinds of interactional conditions that help learning to grow and to adapt how they communicate with individual learners to cater for diversity among them. Other teachers are less expert.

Language pedagogy has been traditionally seen in terms of 'approaches', 'methods' and 'techniques' (Anthony, 1963). It is true that teachers need to know what to do in the classroom, so these concepts are useful. But ultimately, stimulating growth and catering for diversity is not a question of any of these, but of how well the teacher can communicate with her learners.

\section{REFERENCES}

Abraham, R. and R. Vann. (1987). Strategies of two language learners: a case study. In A. Wenden, and J. Rubin, (Eds.), Learner Strategies in Language Learning, London: Prentice Hall.

Anthony, E. (1963). Approach, method and technique. English Language Teaching Journal 17: 63-67.

Bloom, L. (1970). Language Development: Form and Function in Emerging Grammars, Research Monograph No. 59, Mass.: MIT Press.

Breen, M. (1987). Learner contributions to task design. In C. Candlin, and M. Murphy, (Eds.), Language Learning Tasks, Lancaster Practical Papers in English Language Education, London: Prentice-Hall.

Dechert, H. (1984). Individual variation in language. In H. Dechert, D. Mohle, and M. Raupach, (Eds.), Second Language Productions, Tubingen: Gunter Narr.

Dulay, H. and M. Burt. (1973). Should we teach children syntax? Language Learning 23: 245-58.

Ellis, R. (1989a). Sources of intra-learner variation in language use and their relationship to second language acquisition. In S. Gass, et al. (Eds.), Variation in Second Language Acquisition, Clevedon: Multilingual Matters. 
Ellis, R. (1989b). Are classroom and naturalistic acquisition the same? A study of the classroom acquisition of German word order rules. Studies in Second Language Acquisition, 11:3.

Faerch, C. and G. Kasper. (1980). Processes in foreign language learning and communication. Interlanguage Studies Bulletin, 5: 47-118.

Flynn, S. (1988). Linguistic theory and foreign language learning and teaching. Paper given at Conference on Empirical Research into FLT Methods, Bellagio.

Givon T. (1979). On Understanding Grammar. New York: Academic Press.

Gregroc, A. (1979). Learning/teaching styles: their nature and effects in student learning styles, Reston, Va.: National Association of Secondary School Principals.

Hatch, E. (1974). Second language learning-universals. Working Papers on Bilingualism, 3: 1-18.

Holec, H. (1980). Learner training: meeting needs in self-directed learning. In $\mathbf{H}$. Altman, and C. James, (Eds.), Foreign Language Teaching: Meeting Individual Needs. Oxford: Pergamon.

Kolb, D. (1976). Learning Style Inventory. Boston: McBer.

Krashen, S. (1977). Some issues relating to the monitor model. In H. Brown, C. Yorio, and R. Crymes, (Eds.), On TESOL'77. TESOL.

Lightbown, P. (1984). The relationship between theory and method in second language acquisition research. In A. Davies, C. Criper, and A. Howatt, (Eds.), Interlanguage. Edinburgh: Edinburgh University Press.

Long, M., and C. Sato. (1983). Classroom foreigner talk discourse: forms and functions of teachers' questions. In H. Seliger and M. Long, (Eds.), Classroom Oriented Research in Second Language Acquisition. Rowley, Mass.: Newbury House.

Meisel, J. (1983). Strategies of second language acquisition: More than one kind of simplification. In R. Andersen, (Ed.), Pidginization and Creolization as Language Acquisition, Rowley, Mass., Newbury House.

Naiman, N., M. Fröhlich, H. Stern, and A. Todesco. (1978). The Good Language Learner. Research in Education No. 7, Toronto: Ontario Institute for Studies in Education.

Pienemann, M. (1984). Psychological constraints on the teachability of languages. Studies in Second Language Acquisition, 6: 186-214.

Pienemann, M. (1985). Learnability and syllabus construction. In K. Hyltenstam, and M. Pienemann, (Eds.), Modelling and Assessing Second Language Acquisition. Clevedon: Multilingual Matters.

Prabhu, N. (1985). Coping with the unknown in language pedagogy. In R. Quirk, and H. Widdowson, (Eds.), English in the World: Teaching and Learning the Language and Literatures. Cambridge: Cambridge University Press. 
Nicholas, H. (1986). The acquisition of langauge as the acquisition of variation. Australian Working Papers in Language Development, 1: 1-30.

Nunan, D. (1988). The Learner-Centred Curriculum. Cambridge: Cambridge University Press.

Reiss, M. (1985). The good language learner: another look. The Canadian Modern Language Review, 41: 511-523.

Rubin, J. (1975). What the 'good language learner' can teach us. TESOL Quarterly, $9(1): 41-51$.

Seliger, H. (1984). Processing universals in second language acquisition. In F. Eckman, L. Bell, and D. Nelson, (Eds.), Universals of Second Language Acquisition, Rowley, Mass.: Newbury House.

Stern, H. (1975). What can we learn from the good language learner. The Canadian Modern Language Review, 31: 304-18.

Wagner-Gough, J. (1975). Comparative studies in second language learning, MA Thesis, UCLA, California.

Wells, G. (1986). The Meaning Makers: Children Learning Language and Using Language to Learn. London: Hodder and Stoughton.

Wenden, A. (1986). What do second-language learners know about their language learning? A second look at retrospective accounts. Applied Linguistics, 7: 186205.

Wesche, M. (1981). Language aptitude measures in streaming, matching students with methods and diagnosis of learning problems. In K. Diller, (Ed.), Individual Differences in Language Learning Aptitude, Rowley, Mass.: Newbury House.

Widdowson, H. (1978). Teaching Language as Communication. Oxford: Oxford University Press.

Willing, K. (1988). Learning Styles in Adult Migrant Education, Adelaide, Australia: National Curriculum Resource Centre.

Witkin, H. C. Moore, D. Goodenough, and P. Cox. (1977). Field-dependent and field independent cognitive styles and their educational implications. Review of Educational Research, 47.

\section{NOTES}

1. This paper was delivered as a keynote conference address in Vancouver at the BC TEAL conference in March 1989.

\section{THE AUTHOR}

Rod Ellis is head of The Department of English Language Teaching at Ealing College of Higher Education. He is the author of Understanding Second Language Acquisition, and the editor of SLA in Context. 